Duje Veić

Wojciech Sulisz

Rohan Soman

http://dx.doi.org/10.21278/brod70302

\title{
EFFECT OF BREAKING WAVE SHAPE ON IMPACT LOAD ON A MONOPILE STRUCTURE
}

UDC 52-782:621.3.016.3

Original scientific paper

\begin{abstract}
Summary
A numerical model is derived to investigate the effect of breaking wave shape on impact load on a monopile structure. The derived model combines potential flow model with a Navier-Stokes/VOF solution. The analysis indicates that the breaking wave impact on a monopile structure results in an extremely rapid increase of pressure to high amplitudes. The peak impact pressure occurs in the region below the overturning wave jet. The breaking wave impact leads to extremely high slamming forces. It is observed that the slamming coefficient corresponding to the peak impact force approaches $2 \pi$. The area directly affected by the impact force is much higher than the impact area considered in engineering practice. Moreover, the analysis shows that the vertical load distribution is far more realistic than a rectangular shape distribution commonly applied in engineering practice. The results also show that the parameters of the rectangular shape distribution applied in engineering practice are complex function of the breaking wave shape and cannot be uniquely defined beforehand. This is because the vertical load distribution strongly depends on breaking wave shape and it is difficult to uniquely approximate such a complex load distribution by a rectangle. The derived results are compared with experimental data from laboratory experiments on irregular breaking wave loads on a monopile structure. Numerical results are in reasonable agreement with experimental data.
\end{abstract}

Key words: $\quad$ breaking wave; wave impact forces; wave impact load distribution; monopile structure; Computational Fluid Dynamics

\section{Introduction}

The prediction of wave loads on maritime structures is of fundamental importance for coastal and offshore engineering. For slender cylindrical structures the breaking wave impact load is a dominant component of hydrodynamic load. Although many studies have been conducted on the interaction between breaking wave and a vertical cylindrical structure, much uncertainty remains. A better understanding of the phenomena may lead to an improved design methodology and eventually to optimization of numerous coastal and offshore structures, including monopile support structures for offshore wind turbines. 
In general, the prediction of wave loads on maritime structures must include nonlinear wave load component that may exceed a corresponding first-order quantity (Sulisz, 1998, 2013) several folds. However, for slender vertical cylindrical structures, especially located in relatively shallow waters, wave impact load due to breaking waves constitute a dominant component of the total load and it must be included in the design analysis. The problem is that the breaking wave impact on a vertical cylindrical structure is a complex 3D phenomenon, characterized by very short durations and extremely high pressures.

Up to now, the interaction between breaking waves and vertical cylindrical structures have mainly been studied experimentally. However, the laboratory measurements are very challenging and uncertainties are high. The values of measured peak pressure are very scattered, even when experimental conditions are repeated such as in the study of Zhou et al. (1991). The peak pressure generally range between $1-50 \rho c_{b}{ }^{2}$, where $c_{b}$ is the wave phase speed. Moreover, the disadvantage of experimental studies is that the resolution of the pressure measuring points is relatively low which makes complete understanding of the phenomenon difficult. Measurements from pressure transducers are usually obtained only every 10-15 degree around the cylindrical span (Hildebrandt \& Schlurmann 2012), which is not sufficient to conduct a detailed analysis of breaking wave impact on a cylindrical structure.

The application of numerical model enables us to evaluate impact pressures on the structure with high spatial and temporal resolution. Therefore, the results from numerical model can help to improve the understanding of the impact of breaking waves on a structure. In the last two decades, numerous numerical studies have been conducted on the attack of breaking waves on a vertical cylinder. The typical numerical models are based on the solution of the Navier-Stokes (NS) equations for a two-phase incompressible flow by applying the finite volume method. These numerical models can represent the breaking wave characteristic with sufficient accuracy, as shown by Chella et al. (2015) where the numerical results are validated with experimental data of Ting \& Kirby (1996). The numerical solution of the breaking solitary wave impact on a cylinder is successfully validated with the laboratory PIV measurements by Mo et al. (2013). The potential of the numerical models for calculation of the violent wave loads on a monopile structure is presented in study of Bredmose \& Jacobsen (2010, 2011). However, their numerical results were not compared with experimental data. Xiao \& Huang (2015) conducted analysis on breaking solitary wave loads on a pile installed at different positions along an inclined bottom. The computed breaking wave forces from their study are consistent with the numerical results of Mo et al. (2013). The results from the study of Xiao \& Huang (2015) show that the reduction of wave loads can be achieved by a proper selection of the location of a pile on a sloping beach.

Choi et al. (2015) investigated the effect of the vibration of a structure on hydrodynamic loads. They validated their numerical model with the filtered and the Empirical Mode Decomposition data from the study of Irschik et al. (2002), which are also used for the validation of the numerical model of Kamath et al. (2016). Kamath et al. (2016) investigated different stages of the plunging breaking wave impact on a vertical cylinder. A similar approach was applied in laboratory experiments by Wienke et al. (2001). Both studies show that the location of the cylinder with respect to the wave breaking point has a significant effect on breaking wave forces. The highest force occurs when the overturning wave jet hits the cylinder just below the wave crest level, and the lowest force is obtained when the wave breaks behind the cylinder.

While the most numerical studies include analysis of wave impact force, the pressure and load distribution on the structure during the wave impact are rarely discussed. In recent study of Ghadirian et al. (2016), discussion on the impact pressure distribution is mainly 
related to the validation of the numerical model. More detailed discussion on the impact pressure distribution during the wave impact is provided by Hildebrandt \& Schlurmann (2013). They investigated temporal impact pressure distribution on the tripod foundation due to phase-focused breaking wave attack. The model is validated with measured wave elevations and impact pressures obtained from the large scale model tests (1:12). By integrating the computed impact pressures around the structure, the temporal characteristic of the vertical load distribution is estimated. The maximum obtained slamming coefficient is $C_{s}=1.1 \pi$, which is considerably lower than the slamming coefficients assessed by applying a simplified approach by Wienke (2001), $C_{s}=2 \pi$.

The effect of the breaking wave shape on the characteristic of the impact pressures and the vertical load distribution has not been investigated so far. The objective of this study is to investigate the effect of the breaking wave shape on the impact wave loads on a monopile structure. The derived results are compared with experimental data from laboratory experiments conducted on irregular breaking wave impact on a monopile structure.

\section{Theoretical models}

\subsection{Analytical approach}

Te inline force on the slender cylindrical structures excited by the breaking wave is usually calculated as:

$$
F=F_{M}+F_{i}
$$

The load $F_{M}$ in this study is approximated by the Morison's equation (Morison et al., 1950), which is calculated assuming corrections presented by Rainey (1989) for cylinder where the axial dimension is not slender. The impact load $F_{i}$ induced by the breaking wave is calculated according to the recommendations specified in DNV $(2010,2014)$ and IEC (2005). According to $\operatorname{DNV}(2010,2014)$ :

$$
F_{i}=\frac{1}{2} \rho C_{s} A u^{2}
$$

where $A$ is the area on the structure which is exposed to the slamming force, and $C_{s}$ is the slamming coefficient. The velocity $u$ should be taken as $1.2 c_{b}$ of the breaking wave height $H_{b}$. The area exposed to the wave impact corresponds to the height of $0.25 H_{b}$ and the azimuth angle $45^{\circ}$.

$$
A=\frac{45}{360} D \pi \frac{H_{b}}{4}
$$

For the smooth cylindrical surface the slamming coefficient is in the range $3<C_{s}<2 \pi$. According to IEC (2005), the impact force is calculated based on a simplified approach proposed by Wienke (2001).

$$
F_{i}(t)=\rho c_{b}^{2} R C_{s}(t) \lambda \eta_{b}
$$

where the slamming coefficient $C_{s}(t)$ is adapted from a simplified solution of an infinitely long cylinder hitting the calm water with the constant speed. The curling factor $\lambda$ defines the vertical area of the impact with respect to the wave crest height $\eta_{b}$. In the study of Wienke \& Oumeraci (2005) the curling factor is estimated semi-empirically according to the experimentally measured impact force and the maximum theoretical value of the slamming 
coefficient $C_{s}(t=0)=2 \pi$. For the case of plunging breaking wave impact on the vertical pile Wienke\&Oumeraci (2005) assessed $\lambda=0.4-0.6$.

\subsection{Numerical approach}

A numerical model used in this study is based on the decomposition technique suggested by Paulsen et al. (2014), where the wave propagation in the outer region is solved by applying a fully nonlinear potential flow model, OceanWave3D, while the process of wave breaking and the breaking wave impact on a structure is derived by applying the NS equations and the open-source CFD toolbox OpenFoam ${ }^{\circledR}$.

The NS equations are solved by applying the Volume of Fluid (VOF) method. The incompressible NS-VOF set of equations are discretized using a finite volume approximation on unstructured grids. The conservation of mass is governed by the continuity equation:

$$
\nabla \cdot \mathbf{u}=0
$$

where $\mathbf{u}=(u, v, w)$ and $u, v$ and $w$ are the velocity components in the Cartesian coordinate system. The incompressible Navier-Stokes equation is:

$$
\frac{\partial}{\partial t} \rho \mathbf{u}+\nabla \cdot(\rho \mathbf{u}) \mathbf{u}^{T}=-\nabla p^{*}-(\mathbf{g} \cdot \mathbf{x}) \nabla \rho+\nabla \cdot(\mu \nabla \mathbf{u})
$$

where, $\rho$ is the density, $p^{*}$ is the pressure in excess of the hydrostatic pressure, $\boldsymbol{g}$ is the acceleration due to gravity, $\mu$ is the dynamic molecular viscosity. The free surface separating the air and water phase is captured using a volume of fluid surface capturing scheme, which solves the following equation for the water volume fraction $\alpha$ :

$$
\frac{\partial \alpha}{\partial t}+\nabla \cdot \mathbf{u} \alpha+\nabla \cdot \mathbf{u}_{r} \alpha(1-\alpha)=0
$$

In which $\boldsymbol{u}_{r}$ is the relative velocity, which helps to retain a sharp water-air interface (Berberović et al., 2009). The marker function $\alpha$ is 1 when the computational cell is filled with water and 0 when it is empty. In the free surface zone the marker function will have a value in the interval $\alpha \in[0 ; 1]$ indicating the volume fraction of water and air, respectively. The fluid density and viscosity are assumed continuous and differentiable in the entire domain and the following linear properties are adopted:

$$
\begin{aligned}
& \rho=\alpha \rho_{w}+(1-\alpha) \rho_{a} \\
& \mu=\alpha \mu_{w}+(1-\alpha) \mu_{a}
\end{aligned}
$$

The time step is controlled by adaptive time stepping procedure based on CourantFriedrichs-Lewy criterion. For all the computations, the maximum Courant number is kept below 0.2 . The symmetry plane is introduced and only half of the domain is considered. The width of the numerical domain is $5 D$. The solution of the NS-VOF in the inlet and outlet zones are relaxed towards the known solution of the potential flow (Fig. 1).

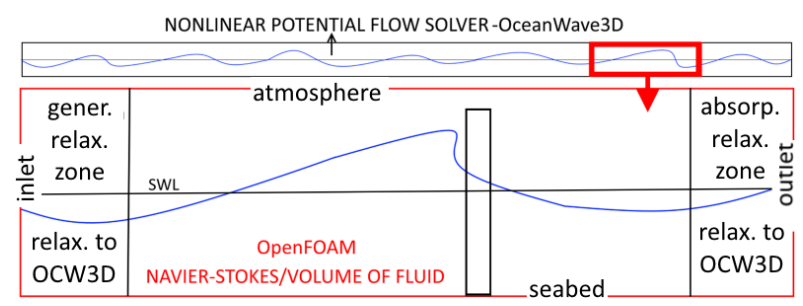

Fig. 1 Decomposed numerical domain 
At the atmosphere boundary inlet/outlet boundary conditions are applied. At the seabed and the lateral boundary the slip condition is applied. Moreover, the slip condition is also applied on the monopile structure, as a result the viscous effects on wave loads are neglected. In the area of the breaking wave impact on the structure, the viscous effect can be neglected due to impulsive loading, while in the area below the breaking wave impact, which is characterized by an oscillating flow, the inertia forces dominate due to a low KeuleganCarpenter number $K C<15$ (e.g. Lupieri \& Contento, 2016).

The sharpness of the air-water interface where $\alpha \in[0 ; 1]$ depends on the size of the computational grid. The thickness of the air-water interface is higher for the coarser computational grid. The density of the air-water mixture depends on the marker function $\alpha$. For the higher thickness of the air-water interface, the rate of change from $\rho=\rho_{a}$ to $\rho=\rho_{w}$ is slower, which affects the pressure in the momentum equation. As the thickness of the airwater interface is higher, the damping effects are stronger (Veic, 2018). Fig. 2 shows how the thickness of the air-water interface affects the magnitude of the hydrodynamic force and the peak impact pressure.

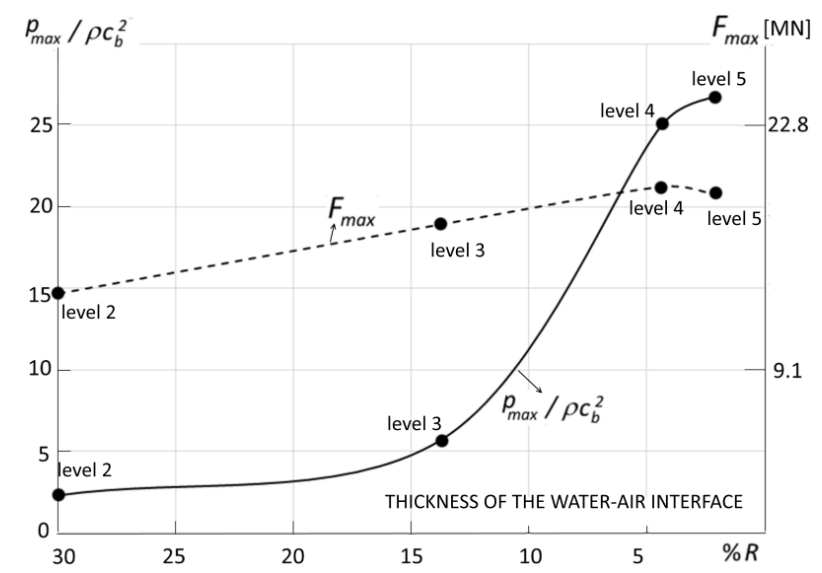

Fig. 2 Effect of the thickness of air-water interface on the impact pressure and the impact force

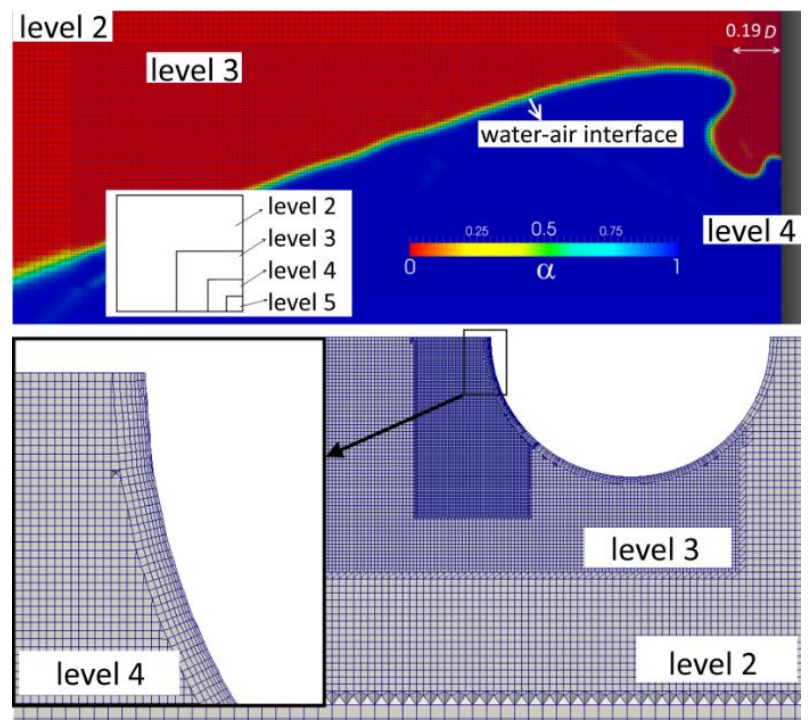

Fig. 3 The computational grid refinement in the zone of the wave impact

If the thickness of the air-water interface tends to zero, the impact pressure stabilizes. The computed peak pressure is almost 10 times higher when the air-water interface thickness is $\approx 0.02 R$, compare to the thickness of the air-water interface equal to $0.3 R$. The effect of the 
thickness of the air-water interface on the magnitude of the impact force is less pronounced. The computed peak force for the air-water interface thickness $0.3 R$ is only 1.5 times lower than for the thickness of air-water interface equal to $0.02 R$. The difference between the magnitude of the force for the thickness of air-water interface $0.04 R$ and $0.02 R$ is usually less than $5 \%$. In order to provide an adequate accuracy with the acceptable computation cost, the calculations were conducted for the thickness of air-water interface equal to $0.04 R$. This is achieved by applying the size of the computational cells in the zone of the wave impact $d x=d y=d z \approx 0.006 D$ (Fig. 3).

\subsection{Results}

The vertical impact load distribution for selected cases of the breaking wave impact, characterized by the different steepness of a wave front are presented. The selected cases refer to the plunging breaking with breaking location slightly before the structure, so that the overturning wave jet hits the monopile just below the wave crest level. This is usually identified as the most violent breaking wave stage. The range of the length of the overturning wave jet analysed in this study is between $l=0.2 R-0.5 R$ (Fig. 4). The breaking wave celerity, $c_{b}$, is identified as the horizontal water particle velocity at the toe of the overturning wave jet, while the curling factor, $\lambda$, is estimated as the distance from the toe of the overturning wave jet to the wave crest height (Fig 4). The monopile diameter is $D=7.2 \mathrm{~m}$.

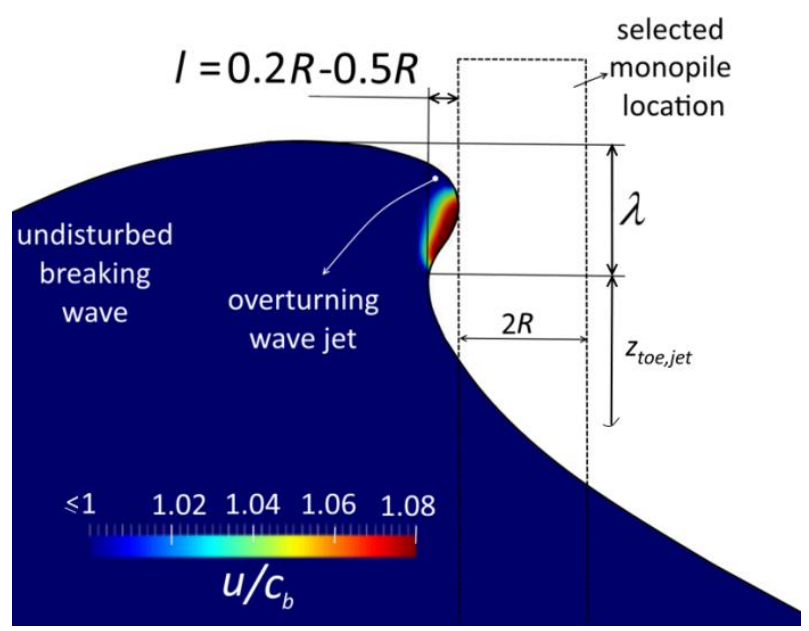

Fig. 4 Geometrical estimation of the breaking wave parameters $l, c b$ and $\lambda$

In order to obtain the desired breaking wave shapes, different wave generation techniques are applied including the propagation and transformation of irregular wave over the flat seabed (case 1) and over the sloped seabed $m=1: 20$ (case 2), generation of phasefocused breaking wave (case 3), and propagation of monochromatic waves over a sloped seabed $m=1: 10,1: 20,1: 50,1: 100$ (cases 4.1-4.4 and cases 5.1-5.3). The main geometric wave characteristics for the different cases are presented in Table 1. The case 1 and case 2 describe the irregular breaking wave generated by the OceanWave3D model which corresponds to time series of the wavemaker used in laboratory experiments. For case 1, wave breaks over the flat seabed at $d_{b}=30 \mathrm{~m}$, while for case 2 , wave breaks over the sloping seabed $(m=1: 20)$ at $d_{b}=17 \mathrm{~m}$. The case 3 describes the phase-focused breaking wave, which breaks over the flat seabed at $d_{b}=30 \mathrm{~m}$. For the case of monochromatic waves, the depth at the toe of the sloping seabed is $d_{0}=45 \mathrm{~m}$, while the depth at the tip of the sloping seabed is $d_{t}=27 \mathrm{~m}$. The offshore wave height corresponds to the maximum wave height obtained from experiments presented in section $4, H_{0}=H_{\max }=18.5 \mathrm{~m}$. The chosen offshore wave period for the cases $4.1-4.4$ is $T_{0}=17 \mathrm{~s}$, while for the cases $5.1-5.3$ is $T_{0}=23.5 \mathrm{~s}$. Fig. 5 shows the comparisons of the parameters of breaking waves used in the present study and breaking wave criterion applied in 
DNV (2014). The test case 3 refers to deep water waves, while the other cases refer to intermediate water depths.

Table 1 Characteristic of the analyzed breaking waves

\begin{tabular}{|c|c|c|c|c|c|c|c|c|c|c|c|}
\hline No & Name & Method & $\begin{array}{c}d_{b} \\
{[\mathrm{~m}]}\end{array}$ & $\begin{array}{c}\eta_{b} \\
{[\mathrm{~m}]}\end{array}$ & $\begin{array}{c}H_{b} \\
{[\mathrm{~m}]}\end{array}$ & $\begin{array}{c}L_{b} \\
\mathrm{~m}]\end{array}$ & $\begin{array}{c}T_{b} \\
{[\mathrm{~s}]}\end{array}$ & $\begin{array}{c}L_{b}{ }^{\prime} \\
{[\mathrm{m}]}\end{array}$ & $\begin{array}{c}H_{0} \\
{[\mathrm{~m}]}\end{array}$ & $\begin{array}{c}T_{0} \\
{[\mathrm{~s}]}\end{array}$ & $\begin{array}{c}L_{0} \\
{[\mathrm{~m}]}\end{array}$ \\
\hline 1 & Case1 & Irreg. flat & 30.0 & 12.4 & 16.0 & 250 & 14.8 & 23 & $/$ & $/$ & $/$ \\
\hline 2 & Case2 & Irreg. $m=1 / 20$ & 17.1 & 9.9 & 15.7 & 329 & 14.8 & 4 & $/$ & $/$ & $/$ \\
\hline 3 & Case3 & Phase focused & 30.0 & 8.1 & 11.0 & 111 & 7.4 & 5 & $/$ & $/$ & $/$ \\
\hline 4 & Case4.1 & Reg. $m=1 / 10$ & 27.0 & 14.9 & 19.9 & 277 & 17.0 & 13 & 18.5 & 17.0 & 322 \\
\hline 5 & Case4.2 & Reg. $m=1 / 25$ & 28.6 & 16.1 & 21.0 & 302 & 17.0 & 20 & 18.5 & 17.0 & 322 \\
\hline 6 & Case4.3 & Reg. $m=1 / 50$ & 29.3 & 16.7 & 21.2 & 320 & 17.0 & 25 & 18.5 & 17.0 & 322 \\
\hline 7 & Case4.4 & Reg. $m=1 / 100$ & 31.3 & 17.0 & 22.0 & 329 & 17.0 & 34 & 18.5 & 17.0 & 322 \\
\hline 8 & Case5.1 & Reg. $m=1 / 10$ & 27.0 & 17.6 & 23.0 & 302 & 21.1 & 14 & 18.5 & 23.5 & 495 \\
\hline 9 & Case5.2 & Reg. $m=1 / 25$ & 27.0 & 18.9 & 23.4 & 329 & 21.1 & 19 & 18.5 & 23.5 & 495 \\
\hline 10 & Case5.3 & Reg. $m=1 / 50$ & 30.2 & 20.0 & 24.5 & 392 & 21.1 & 31 & 18.5 & 23.5 & 495 \\
\hline
\end{tabular}

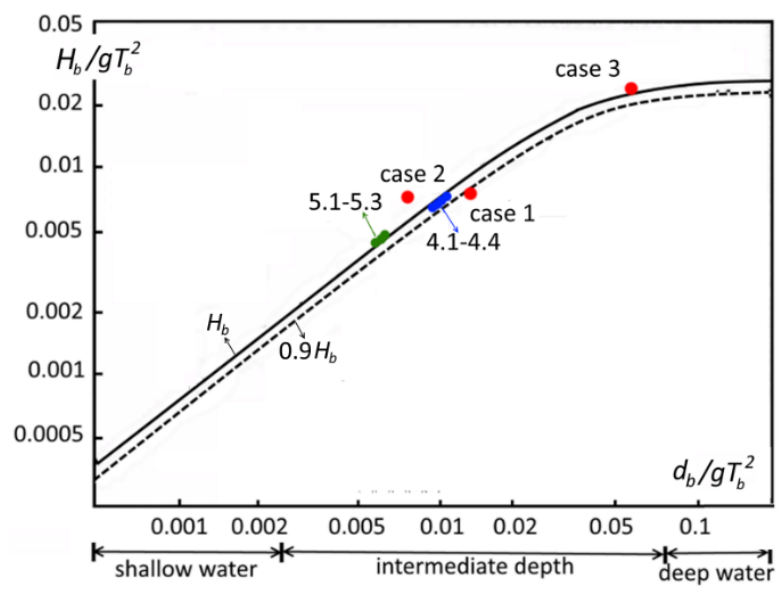

Fig. 5 Parameters of breaking waves and breaking wave criterion applied in DNV(2014)

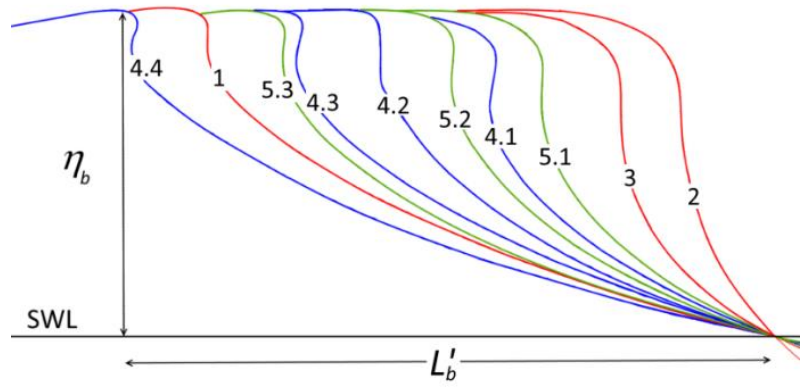

Fig. 6 The shape of the wave fronts scaled to match identical wave crest height

The steepness of the breaking wave front is different in each analysed case. In order to show the differences between the profiles of the breaking wave front, all selected cases are scaled to match the identical crest height (Fig. 6). The range of the wave crest front steepness parameter $s_{f}=\eta_{b} / L$ ' (Bonmarin, 1989) is presented in Fig. 7. For the case of monochromatic waves, the parameter of the breaking wave crest front steepness is higher when wave breaks over the steeper slopes. For an identical slope, the longer offshore waves leads to higher 
steepness of the breaking wave front. The highest values of the crest front steepness parameter are achieved for the case of phase-focused breaking wave and irregular breaking wave over a sloping seabed. Table 2 shows values of the estimated breaking wave celerity, the curling factor, and the length of the overturning wave jet for all selected cases.

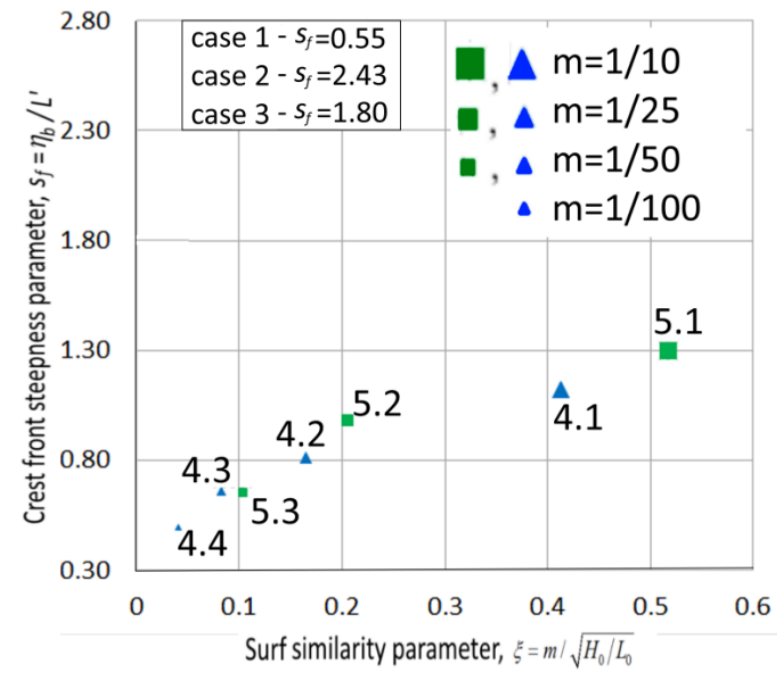

Fig. 7 The range of the crest front steepness parameter

Table 2 Estimated values of the breaking wave parameters $l, c_{b}$ and $\lambda$

\begin{tabular}{|c|c|c|c|c|c|}
\hline No & Name & Method & $c b[\mathrm{~m} / \mathrm{s}]$ & $l / R$ & $\lambda$ \\
\hline 1 & Case1 & Irreg. flat & 17.4 & 0.19 & 0.13 \\
\hline 2 & Case2 & Irreg. $m=1 / 20$ & 16.8 & 0.26 & 0.55 \\
\hline 3 & Case3 & Phase focused & 14.4 & 0.20 & 0.45 \\
\hline 4 & Case4.1 & Reg. $m=1 / 10$ & 20.1 & 0.31 & 0.39 \\
\hline 5 & Case4.2 & Reg. $m=1 / 25$ & 20.5 & 0.25 & 0.19 \\
\hline 6 & Case4.3 & Reg. $m=1 / 50$ & 20.8 & 0.28 & 0.15 \\
\hline 7 & Case4.4 & Reg. $m=1 / 100$ & 21.2 & 0.19 & 0.11 \\
\hline 8 & Case5.1 & Reg. $m=1 / 10$ & 20.8 & 0.44 & 0.46 \\
\hline 9 & Case5.2 & Reg. $m=1 / 25$ & 22.1 & 0.25 & 0.27 \\
\hline 10 & Case5.3 & Reg. $m=1 / 50$ & 22.8 & 0.23 & 0.18 \\
\hline
\end{tabular}

\subsubsection{Non-impact force}

Fig. 8 presents the comparison between the computed hydrodynamic force and hydrodynamic force calculated by applying the Morison's equation. For the estimation of the fluid velocity and acceleration, two approaches are used. In the first approach, the wave kinematics are estimated according to the stream function wave theory, which describes the non-linear symmetric waves up to the limit of $H=0.9 H_{b}$. In the second approach, the breaking wave is simulated by applying 2D NS-VOF model. The wave velocity and acceleration field from the numerical model are taken at the position before wave reaches the breaking wave limit. For the breaking wave cases, which are characterized by the low steepness of the breaking wave front, the Morison's force derived by applying the stream function wave kinematics, provides relatively good approximation of the non-impact force (case 1). As the steepness of the breaking wave front increases, the Morison's force derived by applying the stream function wave kinematics is not appropriate for approximation of the non-impact 
force. However, the Morison's force based on the wave kinematics derived by applying NSVOF model approximates the computed non-impact force fairly well.

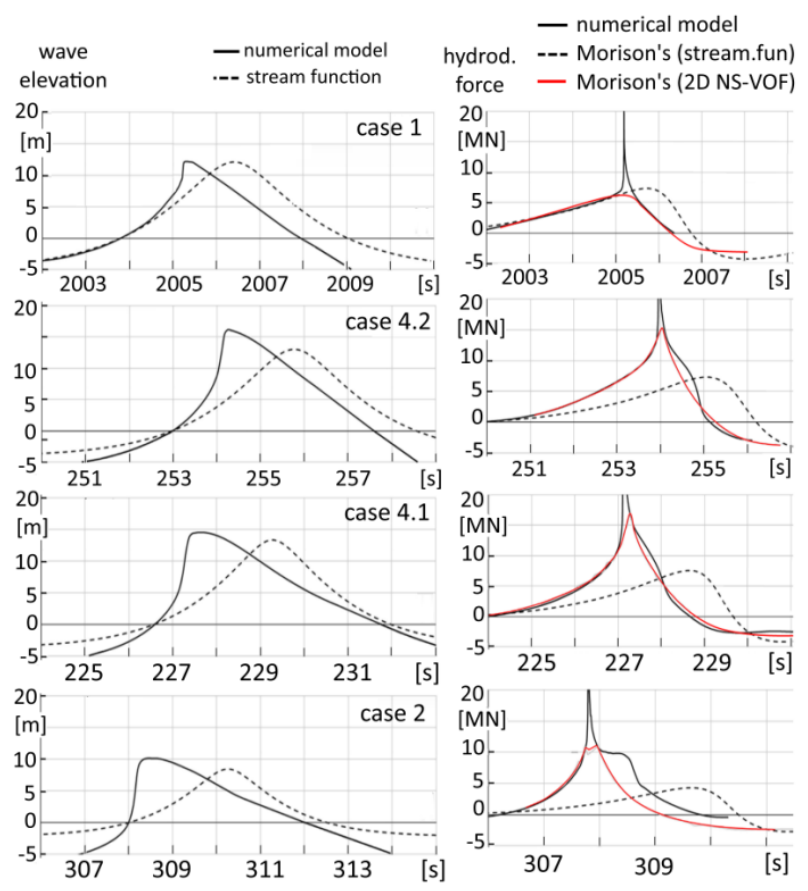

Fig. 8 Comparison between the computed inline force and the Morison's force

\subsubsection{Impact force}

This section presents comparison between the impact forces obtained by applying the derived model and results of simplified approaches applied in engineering practice. Numerical results for the case 4.4 show that the presence of the wave run-up considerably interfere with the interaction between the overturning wave jet and a monopile structure. Fig. 9 shows that the impact force on the structure is damped and, as a consequence, reduced due to the interaction between the overturning wave jet and the wave run-up jet. The results of the case 4.4 are not adequate for a direct comparison with the results from the derived model, hence, the case 4.4 is omitted in the figure.

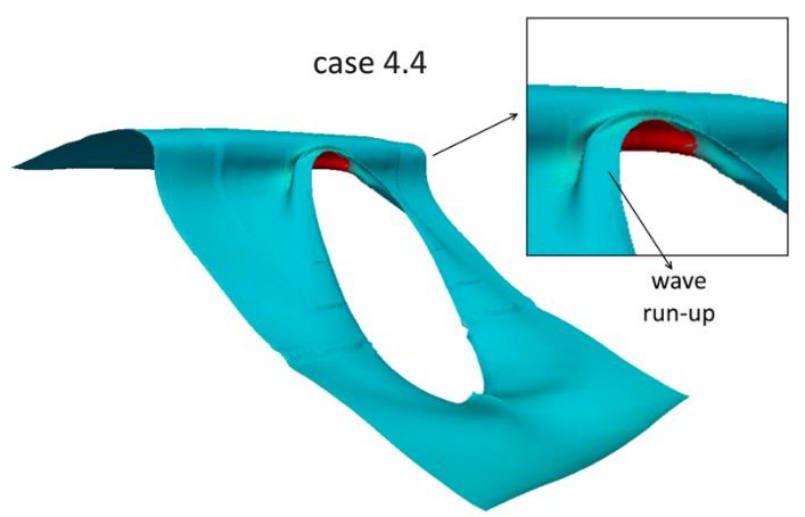

Fig. 9 Interference between the wave run-up and overturning wave jet for case 4.4

It is estimated that the impact force on a monopile structure occurs when dynamic pressure on the structure surface exceeds $p_{d y n}>0.5 \rho c_{b}^{2}$. Fig. 10 presents plots of the impact forces $F_{i}$ for all selected cases. The force is normalized by $F_{i}(t) / \rho R c_{b}{ }^{2} \lambda \eta_{b}$ and is shown in terms of the slamming coefficient $C_{s r}(t)$. The values of the peak slamming coefficient are 
scattered, ranging from $C_{s r}=0.9 \pi$ (case 2) to $C_{s r}=2.1 \pi$ (case 1). Fig. 10 also shows the comparison between the computed slamming coefficient $C_{s r}(t)$ and a corresponding slamming coefficient obtained by applying a simplified approach (Wienke, 2001). The peak of the slamming coefficient in Fig. 10 corresponds to $t=0 \mathrm{~s}$. The time $\mathrm{t}<0 \mathrm{~s}$ refers to the rising impact force phase which cannot be derived from a simplified approach suggested by Wienke (2001), while the time $\mathrm{t}>0 \mathrm{~s}$ refers to the decaying impact force phase. For the time interval $0<\mathrm{t}<0.12 R / c_{b}$ the computed force decays much faster than forces derived from a Wienke approximation.
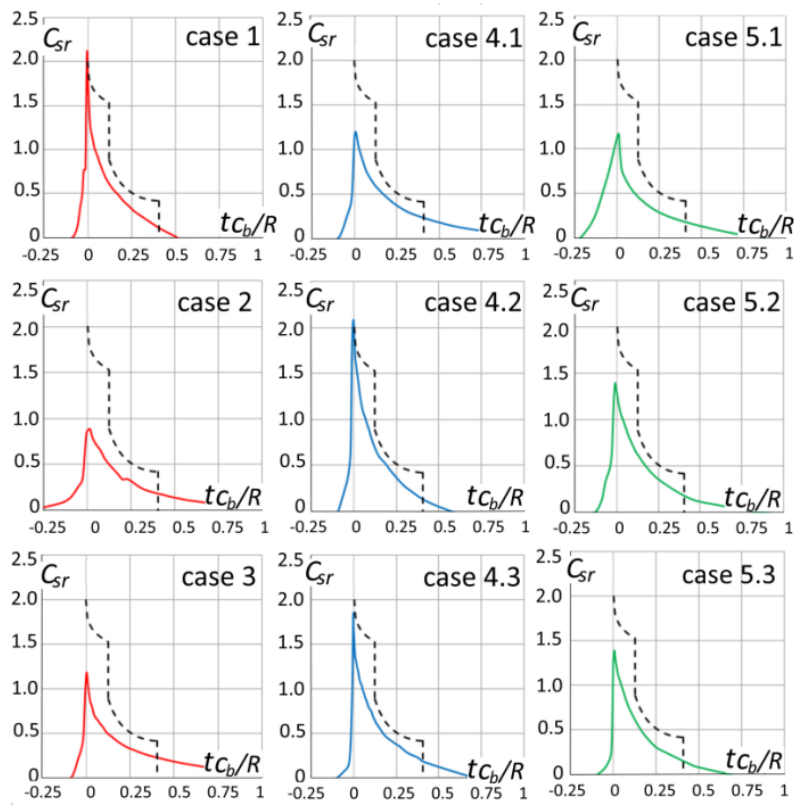

Fig. 10 Slamming coefficients derived from the present model and corresponding results obtained by applying Wienke (2001) approximation ---

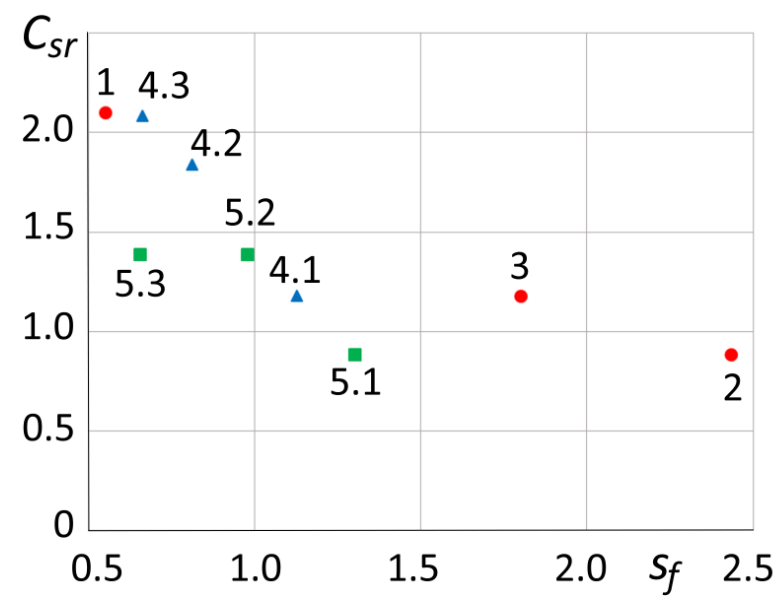

Fig. 11 Dependency between the slamming coefficient $C_{s r}$ and the crest front steepness parameter $s_{f}$

Fig. 11 shows the value of the computed slamming coefficient $C_{s r}$ as a function of the crest front steepness parameter $s_{f}$. The results show that the value of the slamming coefficient $C_{s r}$ is inversely proportional to the steepness of the breaking wave front $s f$.

Fig. 12 shows the computed peak impact forces and corresponding results obtained by applying simplified approaches. The slamming coefficient is considered as $C_{s r}=2 \pi$ for both simplified approaches. The discrepancies between presented results arise from simplification applied in approximate approaches. 


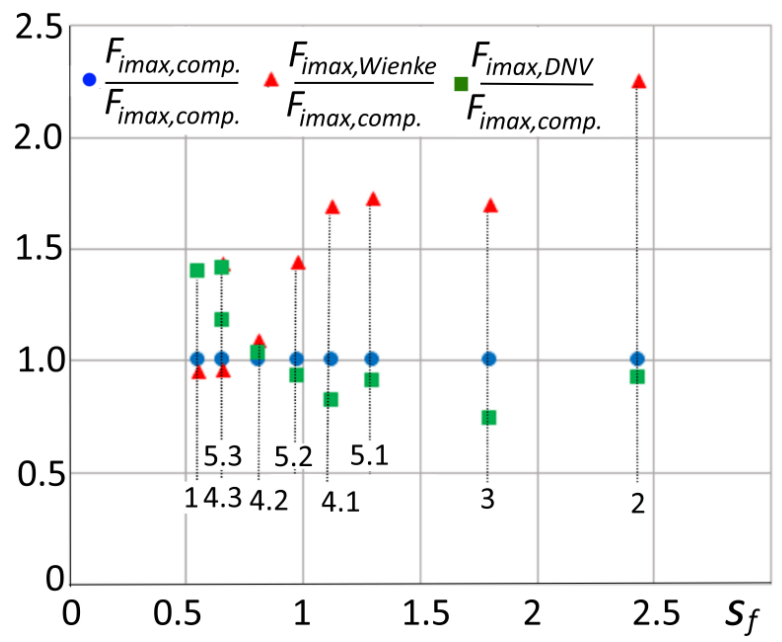

Fig. 12 Computed impact forces and corresponding results obtained by applying simplified approaches Wienke (2001) and DNV $(2010,2014)$

\subsubsection{Vertical load distribution}

The distribution of the impact pressures on the monopile structure is similar for all analyzed cases. The highest impact pressures computed in this study are $p_{\max } \approx 25 \rho c_{b}{ }^{2}$, with the corresponding rising time $t_{p i} \approx 0.025 R / c_{b}$. Those values are very similar to the laboratory measurements conducted by Zhou et al. (1991) and Chan et al. (1995). The highest impact pressure occurs in the region below the overturning wave jet. Fig. 13 shows the shape of the breaking wave profile and corresponding pressure distribution on a structure for the case 4.1. Additionally, Fig. 13 shows vertical impact pressure distribution along the front line of the monopile structure. It can be observed that the highest impact pressure occurs in the region where the overturning wave jet meets the wave run-up on the structure. The vertical pressure distribution on the front is also characterized by a rapid decay of pressure from the peak value.

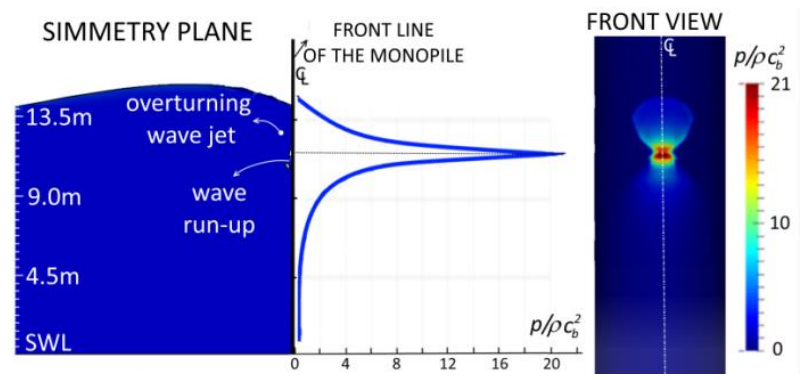

Fig. 13 Computed impact forces and corresponding results obtained by applying simplified approaches

By integrating the pressure around the strips of the monopile structure, the vertical load distribution can be determined. The monopile structure is divided into small strips $d z=0.09 \mathrm{~m}$ and the strip forces are calculated. The obtained vertical impact load distribution is normalized by $\rho R c_{b}^{2} d z$. Fig. 14 shows the obtained slamming coefficients $C_{s}$ at the moment of the maximum impact force for the case 1 and the case 2 . The results show that the peak slamming coefficients occurs in the zone of the highest pressure. The value of the peak slamming coefficient approaches $2 \pi$ for all analysed cases. The slamming coefficient values decay rapidly as we move away from the peak region. The area of the impact load on the structure is significantly higher than the impact area which is defined by the curling factor $\lambda$ (Table 2). 


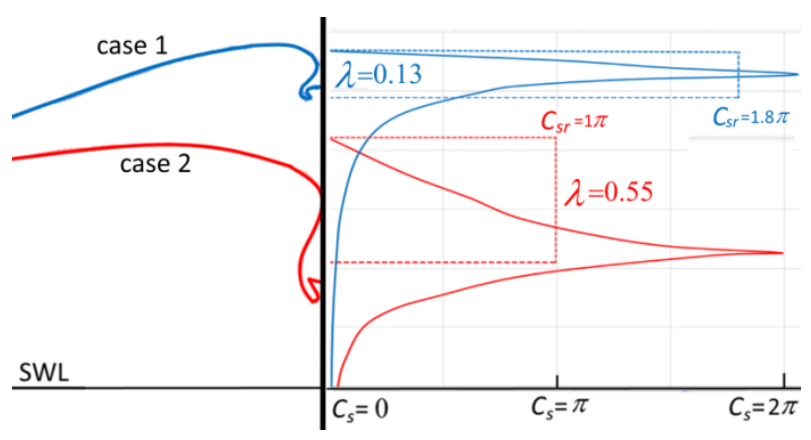

Fig. 14 Approximation of the area under the computed vertical load distribution by the rectangular shape

As mentioned, the approximation of the vertical impact load distribution by the rectangular shape leads to the non-unique and confusing determination of the curling factor and the slamming coefficient. This is presented in Fig. 14, where for a geometrically determined curling factor $\lambda$, the slamming coefficient for the case 1 is $C_{s r}=1.8 \pi$, while for the case 2 is $C_{s r}=1 \pi$.

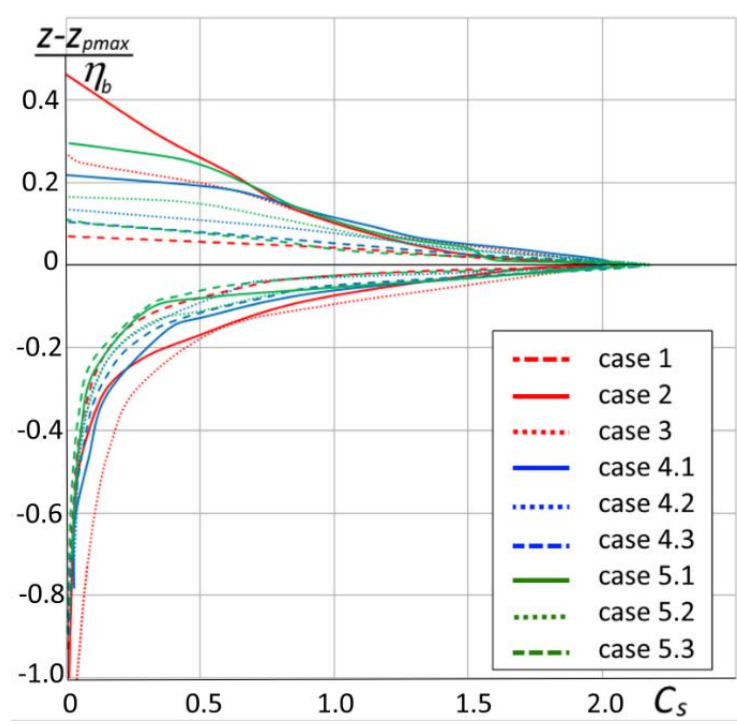

Fig. 15 Vertical impact load distribution

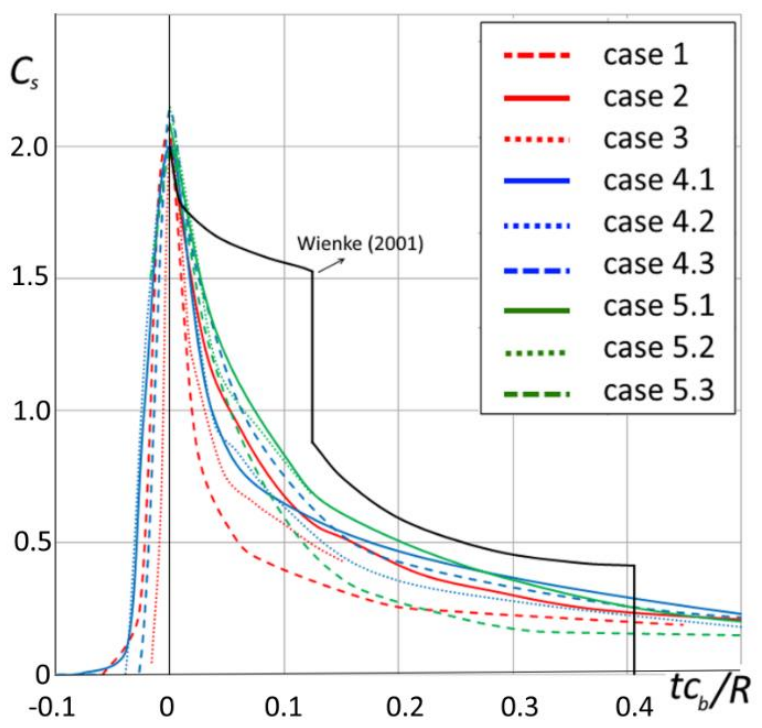

Fig. 16 Temporal impact load distribution at $z_{p m a x}$

Fig. 15 shows vertical impact load distribution for all cases. The slamming coefficient is presented in terms of normalized vertical position, $\left(z-z_{\text {pmax }}\right) / \eta_{b}$, where $z_{\text {pmax }}$ is the vertical location of the maximum impact pressure. For $z>z_{\text {pmax }}$ the impact load distribution can be approximated by a linear function - the maximum value occurs at $z=z_{p \max }$ and zero value is located at $z_{\text {max }}=\eta_{b}$. For $z<z_{\text {pmax }}$ the impact load is characterized by the rapid decay from the peak value $C_{s}=2 \pi$. Fig 16 presents the temporal distribution of impact force on the monopile strip located at $z=z_{\text {pmax }}$. The rising phase of the impact force $(\mathrm{t}<0 \mathrm{~s})$ can be approximated by a linear function. Then, the impact force decays rapidly from the peak as clearly show the plots in Fig. 16.

\subsubsection{Impact force}

The computed impact forces are compared according to suggested impact load distribution for different moments of the impact $C_{s}(z, t)$, and presented in Fig 17. The vertical distribution of the impact load $C_{s}(z, t)$ is shown for 7 different moments in time $t_{0}$ to $t_{6}$. The diagram of the impact load distribution is divided in two parts. For the zone $z>z_{p m a x}$ the impact begins at $t_{0}{ }^{\prime}=-0.9 l / c_{b}$, while for the zone $z<z_{p \max }$ the impact begins arts at $t_{0}=-0.06 R / c_{b}$. For the calculation of the impact force according to the load distribution suggested in the Fig 17, the 
location of the maximum impact pressure $z_{\text {pmax }}$ and the length of the overturning wave jet $l$ is required. These parameters can be obtained from a 2D simulation of breaking wave by applying NS-VOF model. In this analysis it is approximated that the impact pressure occurs approximately at $z_{\text {pmax }}=1.15 z_{\text {toe }, \text { jet }}$.

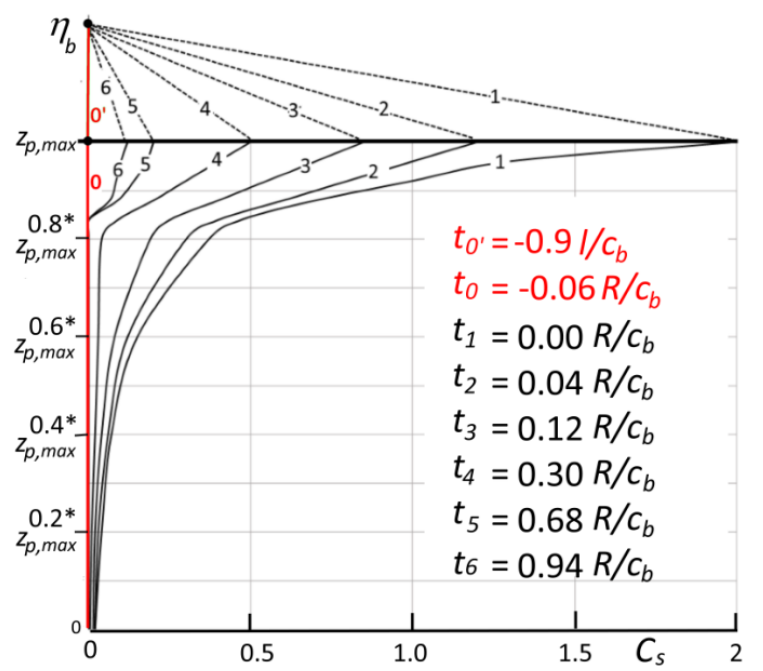

Fig. 17 Suggested impact load distribution in time Cs $(\mathrm{t}, \mathrm{z})$

Fig. 18 shows comparison between the computed and estimated impact force according the aforementioned procedure. The temporal characteristic of the impact force is captured with good accuracy. Discrepancies observed in the impact force peak zone are up to $30 \%$. However, compared to the results obtained from Wienke's simplified approach presented in Fig. 10, the results from suggested procedure provide significantly better approximation of the impact force. These results encourage us for further development of the proposed procedure which may eventually lead to an alternative method for preliminary estimation of the impact forces.
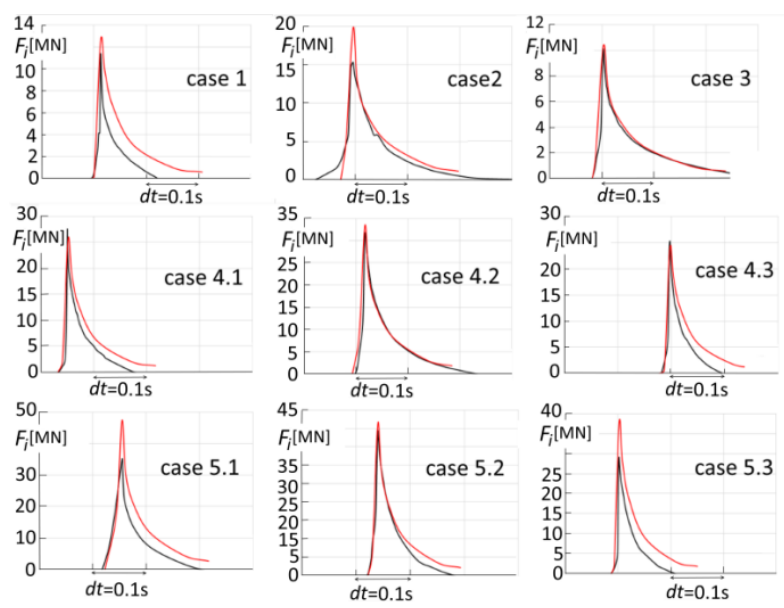

Fig. 18 Comparison between the computed impact forces and approximate solution

\section{Experimental validation case}

This section presents comparison between the results of the presented numerical model and experimental data obtained from laboratory experiments conducted in Deltares, Delft. The 50-years storm conditions in the German Bight were simulated in a wave basin. The parameters of the applied JONSWAP wave energy spectrum were: $H_{s}=10 \mathrm{~m}, T_{p}=13 \mathrm{~s}, \gamma=3.3$. The diameter of the monopile is $D=7.2 \mathrm{~m}$. The model scale is 45 . 
Laboratory experiments were conducted for two scenarios. In the first series of experiments the monopile structure was installed on the flat seabed, $d=30 \mathrm{~m}$. In the second series of experiments the monopile structure was installed at the sand bar at the depth $d=25 \mathrm{~m}$. The slope of the sand bar is $m=1: 21$. The validation of the derived model focus on measurements for which the maximum hydrodynamic force on the structure is recorded. The validation case 1 relates to the breaking wave over the flat seabed, while validation case 2 relates to the breaking wave over the sand bar.

The wave basin has a length of $75 \mathrm{~m}$, a width of $8.7 \mathrm{~m}$, and a maximum water depth of about $1.2 \mathrm{~m}$. Hydrodynamic force and impact pressures were measured during tests and the wave-structure interaction were recorded with a high-frequency video camera. To obtain actual hydrodynamic loads, and remove the effects of structural vibrations the measurements were filtered out (Veic, 2018). The structure was equipped with 10 pressure transducers distributed evenly along the front line of the structure, every $22 \mathrm{~mm}$ in the wave impact zone. A sampling frequency of $1000 \mathrm{~Hz}$ was applied. Waves were generated by a piston-type wavemaker. For each scenario 5 separate tests were conducted. The duration of each test case was $1744 \mathrm{~s}$ ( $\sim 3 \mathrm{~h}$ in full scale) which corresponds to approximately 1000 waves. For the case of the experiments with the sand bar, the breaking wave phenomena occurred more frequently. Taking into account the total number of waves (5000), probability of occurrence of the slamming event in the case of the flat seabed was $0.3 \%$, while in the case of the sand bar was $1.2 \%$. The maximum inline force measured for the case of the sand bar was more than $50 \%$ higher than for the case of the flat seabed.
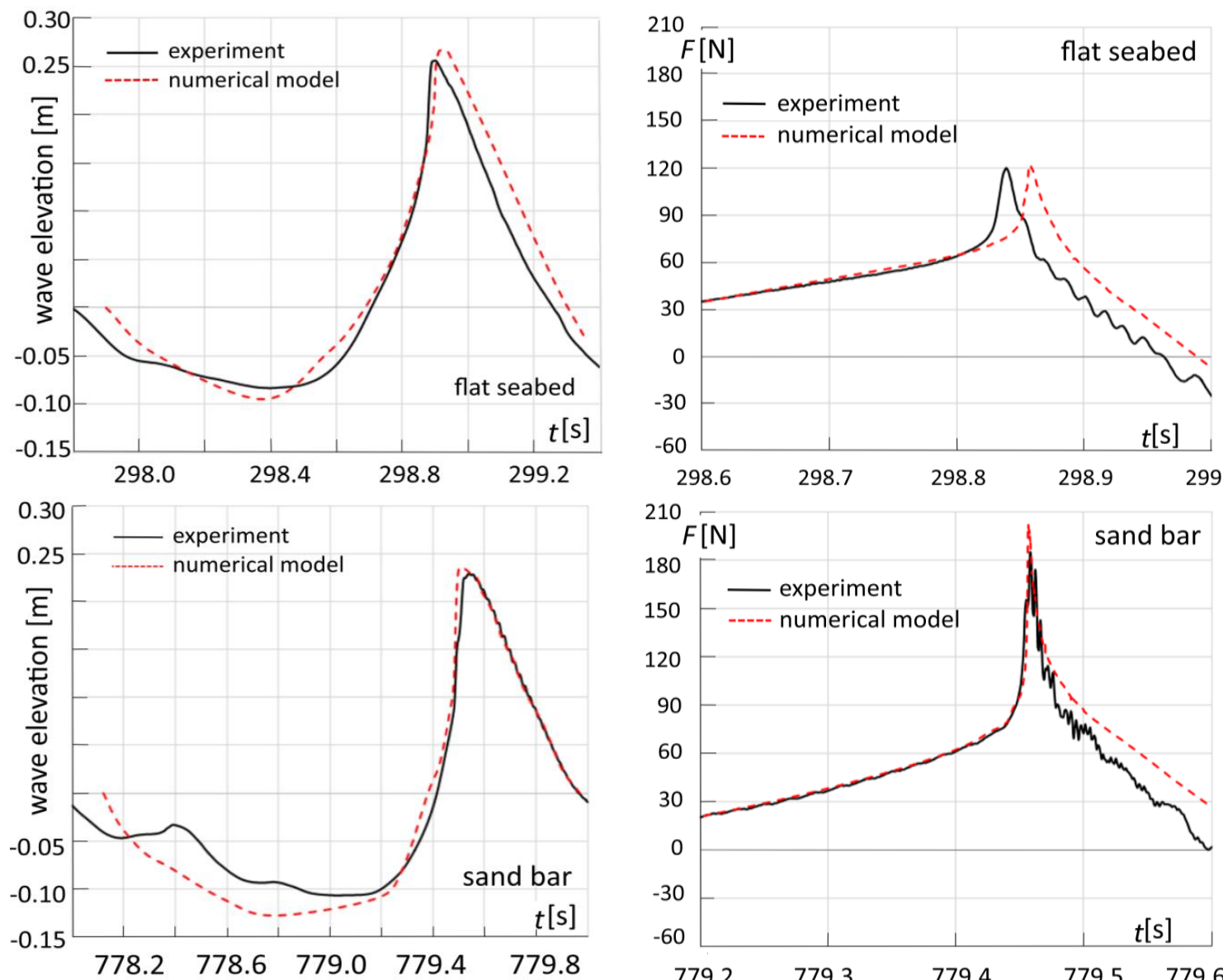

Fig. 19 The comparison between predicted and measured wave elevations

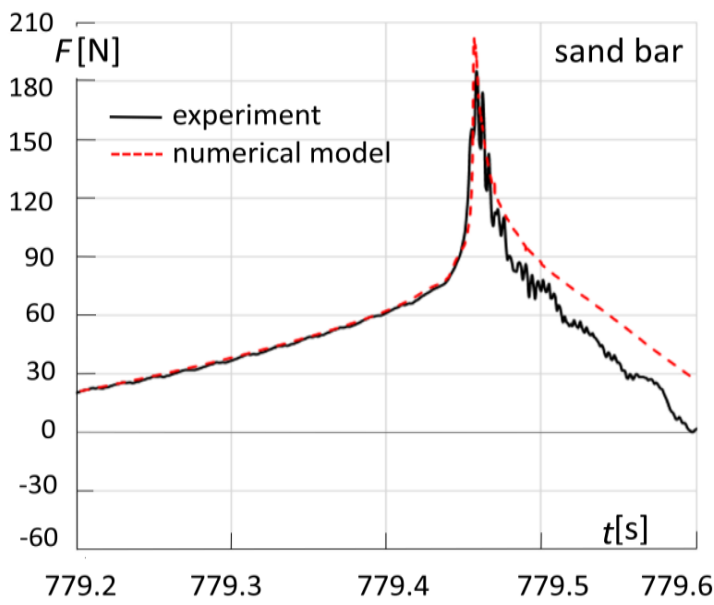

Fig. 20 The comparison between predicted and measured hydrodynamic forces 
The experimental results were reproduced by implementing the kinematic wavemaker boundary condition in the numerical model. The obtained numerical results were compared with experimental measurements of wave elevation, hydrodynamic force, and the pressures along the front line of the monopile. The validation was also conducted by applying the records from the HF-video camera available for the breaking wave over the flat seabed. The comparison between the numerical and experimental wave elevation are presented in Fig. 19. The wave elevation was measured at a distance of $3 \mathrm{D}$ from the monopile centre line position. Fig. 20 shows that the computed forces are in reasonable agreement with experimental data. Small discrepancies are observed only for the peak value of the impact force in the case 2 . These differences may be attributed to the relatively low sampling rate used in measurements, or effects of the air compressibility, which is not taken into account in conducted computations.

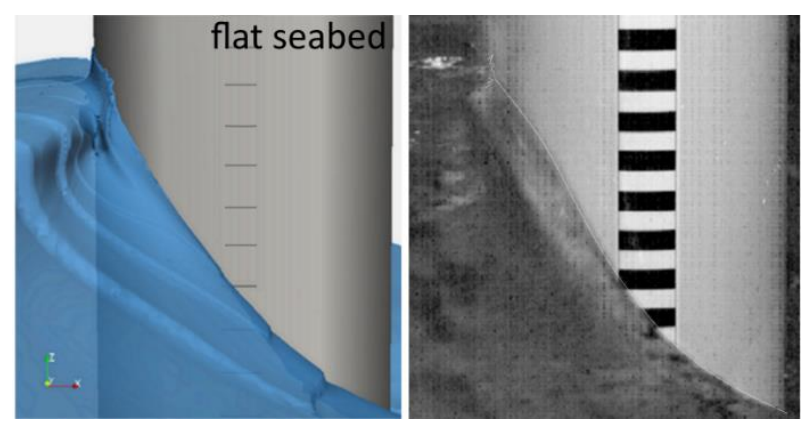

Fig. 20 Snapshot of the breaking wave impact

The snapshot from the HF-video camera for the case 1 is very similar to the numerical visualization (Fig. 21). The numerical results for the case 1 show that wave breaks just in front of the structure so the wave run-up reduces the magnitude of impact force. Fig. 22 shows the magnitude of impact force for the structure moved 1.25R upstream. The computed impact force in this case is 4 time higher. This shows that the problem of the position of a structure is especially important for irregular wave attack on a structure where a wave breaking position is difficult to predict beforehand.

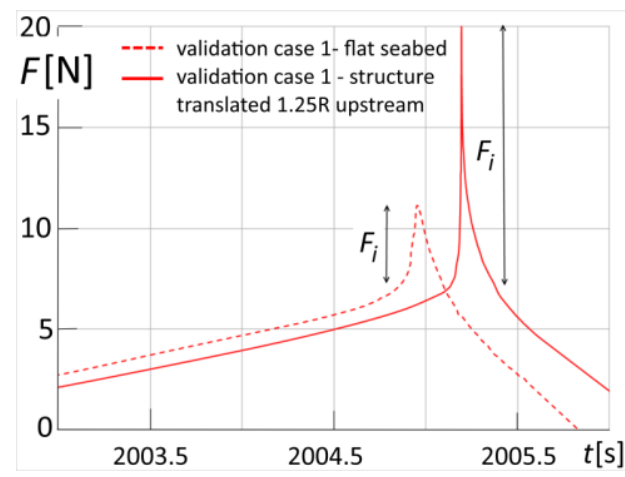

Fig. 21 Computed impact force for the translated monopile structure

Fig. 23 and Fig. 24 show comparison between the computed and measured impact pressures at the front line of the monopile structure. For both cases the numerical results are in excellent agreement with the experimental results. The discrepancies between the numerical and experimental results for case 2 occur basically only in the peak pressure zone. The observed discrepancies may be attributed mainly to the relatively low sampling rate of pressure measurements $(1 \mathrm{kHz})$ which is not sufficient to accurately record pressure in a rising phase. Nevertheless, at the moment of the maximum impact force, which occurs after the 
moment of the peak pressure occurrence at the front line of the monopile (Fig. 24), the values of computed and measured pressures are similar. The results from this section show that the presented numerical model can reproduce experimental results with sufficient accuracy.
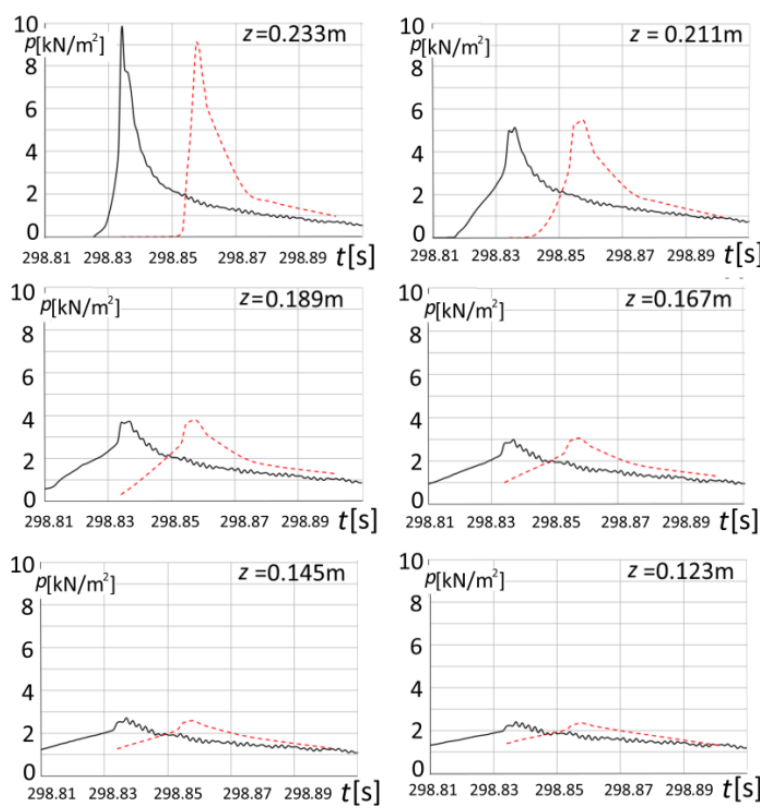

Fig. 23 Comparison of the impact press.-flat seabed
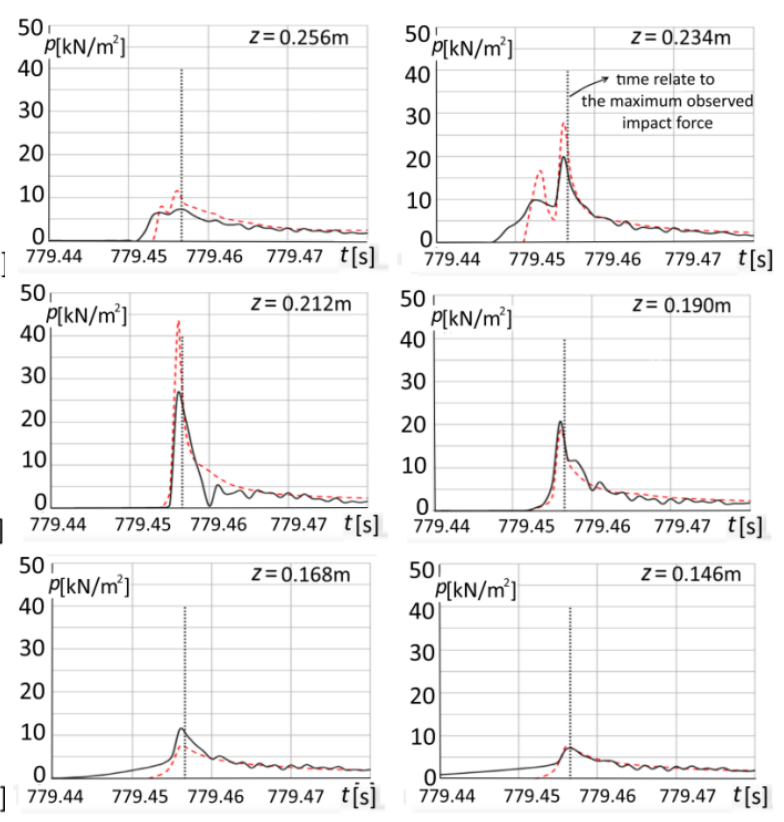

Fig. 24 Comparison of the impact press.-sand bar

\section{Conclusions}

The numerical model is derived to study the effect of the shape of breaking waves on wave impact loads on a monopile structure. The derived model combines potential flow model with a NS VOF solution. The investigations focus on the computation of the vertical impact load distribution arising from the breaking waves of different wave front steepness.

The results show that the highest impact pressure occurs in the region below the overturning wave crest, where the overturning wave crest meets the wave run-up on the structure. The analysis shows that at this location the breaking wave impact is maximum and the slamming coefficient is about $C_{s}=2 \pi$. Away from the peak region, wave impact loads decays rapidly. The area of the impact load on the structure is significantly higher than the impact area defined and applied in engineering practice.

The analysis shows that the approximation of the vertical load distribution by a rectangular is a simplification which cannot uniquely approximate real load distribution arising from breaking wave attack on a monopile structure.

The derived results indicate a possibility for development of improved design methodology for a preliminary estimation of the breaking wave loads on monopile structures. The investigations show that the non-impact wave loads may be derived from the Morison equation, while the breaking wave impact forces may be approximated according to the proposed diagram of the temporal vertical load distribution, $C_{s}(t, z)$.

The derived results are compared with data from laboratory experiments on irregular breaking wave loads. The geometric characteristics of breaking waves obtained in laboratory experiments are successfully reproduced in the numerical domain. Breaking wave forces are computed with sufficient accuracy. Differences between measurements and computations are found only in the very narrow region of the peak values, where computed values are up to 
$10 \%$ higher. These differences may be attributed to the relatively low sampling rate used in measurements, or effects of the air compressibility.

Air pockets, which can be trapped between the overturning wave jet and the structure during the wave impact are compressible and can pass through expansion and contraction phases. This results in the pulsating impact pressure during the wave impact. Influence of the pulsating impact pressure on the total impact loads is expected to be more pronounced for the modal scale than for the prototype scale. As the effects of the air compressibility on the braking wave impact loads may be significant, it is recommended to perform future analysis by applying a compressible numerical model.

\section{ACKNOWLEDGMENTS}

A part of this work was carried out during MareWint project under research area FP7PEOPLE-2012-ITN Marie-Curie Action: “+Initial Training Networks" and during secondment at the Dutch research institute, Deltares, Delft. The authors are indebted to Bo Terp Paulsen, Ph.D. from Deltares for constructive comments.

\section{REFERENCES}

[1] Berberović, E., Van Hinsberg, N. P., Jakirlić, S., Roisman, I. V., \& Tropea, C. (2009). Drop impact onto a liquid layer of finite thickness: Dynamics of the cavity evolution. Physical Review E - Statistical, Nonlinear, and Soft Matter Physics, 79(3). https://doi.org/10.1103/PhysRevE.79.036306

[2] Bonmarin, P. (1989). Geometric properties of deep-water breaking waves. Journal of Fluid Mechanics, 209(1). https://doi.org/10.1017/S0022112089003162

[3] Chan, E. S., Cheong, H. F., \& Tan, B. C. (1995). Laboratory study of plunging wave impacts on vertical cylinders. Coastal Engineering, 25(1-2), 87-107. https://doi.org/10.1016/0378-3839(94)00042-V

[4] ChellaAlagan, M., Bihs, H., Myrhaug, D., \&Muskulus, M. (2015). Breaking characteristics and geometric properties of spilling breakers over slopes. Coastal Engineering, 95, 4-19. https://doi.org/10.1016/j.coastaleng.2014.09.003

[5] Choi, S. J., Lee, K. H., \&Gudmestad, O. T. (2015). The effect of dynamic amplification due to a structure's vibration on breaking wave impact. Ocean Engineering, 96, 8-20.

https://doi.org/10.1016/j.oceaneng.2014.11.012

[6] Ghadirian, A., Bredmose, H., \&Dixen, M. (2016). Breaking phase focused wave group loads on offshore wind turbine monopiles. In Journal of Physics: Conference Series, 753 (9) https://doi.org/10.1016/j.oceaneng.2014.11.012

[7] Hildebrandt, A., \& Schlurmann, T. (2012). Breaking wave kinematics, local pressures, and forces on a tripod structure. Coastal Engineering Proceedings, 1(33) https://doi.org/10.9753/icce.v33.structures.71

[8] Hildebrandt, A. (2013). Hydrodynamics of Breaking Waves on Offshore Wind Turbine Structures (Doctoral dissertation, Technische Informationsbibliothek und Universitätsbibliothek Hannover (TIB)).

[9] Irschik, K., Sparboom, U., \& Oumeraci, H. (2003). Breaking wave characteristics for the loading of a slender pile. In Coastal Engineering 2002: Solving Coastal Conundrums, pp. 1341-1352 https://doi.org/10.1142/9789812791306_0113

[10] Kamath, A., AlaganChella, M., Bihs, H., \&Arntsen, Øivind A. (2016). Breaking wave interaction with a vertical cylinder and the effect of breaker location. Ocean Engineering, 128(September), 105-115. https://doi.org/10.1016/j.oceaneng.2016.10.025

[11] Lupieri, G., \& Contento, G. (2016). A numerical study on the viscous effects of waves travelling past a weakly submerged cylinder. Brodogradnja: Teorija i praksa brodogradnje i pomorske tehnike, 67(4), 6169. https://doi.org/10.21278/brod67405

[12] Mo, W., Jensen, A., \& Liu, P. L. F. (2013). Plunging solitary wave and its interaction with a slender cylinder on a sloping beach. Ocean Engineering, 74, 48-60. https://doi.org/10.1016/j.oceaneng.2013.09.011

[13] Morison, J. R., Johnson, J. W., \&Schaaf, S. a. (1950). The Force Exerted by Surface Waves on Piles. Journal of Petroleum Technology, 2(5), 149-154. https://doi.org/10.2118/950149-G 
[14] Paulsen, B. T., Bredmose, H., \& Bingham, H. B. (2014). An efficient domain decomposition strategy for wave loads on surface piercing circular cylinders. Coastal Engineering, 86, 57-76.

https://doi.org/10.1016/j.coastaleng.2014.01.006

[15] Rainey, R. C. T. (1989). A new equation for calculating wave loads on offshore structures. Journal of Fluid Mechanics, 204(WW3), 295-324. https://doi.org/10.1017/S002211208900176X

[16] Sulisz, W. (1998). Diffraction of nonlinear waves by founded horizontal rectangular cylinder. Journal of Waterway, Port, Coastal, and Ocean Engineering, ASCE, 124, 5, 257-263. https://doi.org/10.1061/(ASCE)0733-950X(1998)124:5(257)

[17] Sulisz, W. (2013). Reflection and transmission of nonlinear water waves at a semi-submerged dock. Archives of Mechanics, 65, 3, 237-260.

[18] Ting, F. C. K., \& Kirby, J. T. (1996). Dynamics of surf-zone turbulence in a spilling breaker. Coastal Engineering, 27(3-4), 131-160. https://doi.org/10.1016/0378-3839(95)00037-2

[19] Wienke, J., Sparboom, U., \& Oumeraci, H..(2001). Breaking wave impact on a slender cylinder. Coastal Engineering Journal2000, 1787-1798. https://doi.org/10.1061/40549(276)139

[20] Wienke, J., \&Oumeraci, H. (2005). Breaking wave impact force on a vertical and inclined slender pile Theoretical and large-scale model investigations. Coastal Engineering, 52(5), 435-462. https://doi.org/10.1016/j.coastaleng.2004.12.008

[21] Xiao, H., \& Huang, W. (2015). Three-dimensional numerical modeling of solitary wave breaking and force on a cylinder pile in a coastal surf zone. Journal of Engineering Mechanics, 141(8). https://doi.org/10.1061/(ASCE)EM.1943-7889.0000834

[22] Zhou, D., Chan, E. S., \& Melville, W. K. (1991). Wave impact pressures on vertical cylinders. Applied Ocean Research, 13(5), 220-234. https://doi.org/10.1016/S0141-1187(05)80046-X

[23] Bredmose, H., \& Jacobsen, N. G. (2010). Breaking Wave Impacts on Offshore Wind Turbine Foundations: Focused Wave Groups and CFD. 29th International Conference on Ocean, Offshore and Arctic Engineering. https://doi.org/10.1016/S0141-1187(05)80046-X

[24] Bredmose, H., \& Jacobsen, N. G. (2011). Vertical Wave Impacts On Offshore Wind Turbine Inspection Platforms. In Proceedings of the ASME 2011 30th International Conference on Ocean, Offshore and Arctic Engineering OMAE2011 June, Rotterdam, The Netherlands https://doi.org/10.1115/OMAE2011$\underline{49785}$

[25] Veic, D. (2018). Effect of the breaking wave shape on the temporal and spatial pressure sistribution around a monopile support structure, Ph.D. Dissertation, IBW-PAN, Polish Academia of Sciences, Gdansk, Poland

[26] Wienke, J. (2001). Druckschlagbelastung auf schlanke zylindrische bauwerke durch brechende wellen: theoretische und großmaßstäbliche laboruntersuchungen, Ph.D Dissertation, Vom Fachbereich für Bauingenieur- und Vermessungswesen der Technischen Universität Carolo-Wilhelmina zu Braunschwei

[27] DNV. (2010). Environmental conditions and environmental loads, DNV-RPC205, DNV GL AS

[28] DNV. (2014). Design of Offshore Wind Turbine Structures, DNV-OS-J101, DNV GL AS

[29] IEC (2005). International EletrotechnicalCommision, IEC 61400-1 Wind Turbines - Part 1: Design

$\begin{array}{lll}\text { Submitted: } & \text { 11.07.2018. } & \begin{array}{l}\text { Duje Veić } \\ \text { dujeveic@ @mail.com }\end{array} \\ \text { Accepted: } & \text { 04.06.2019. } & \text { Institute of Hydro-engineering, Polish Academy of Sciences } \\ & \text { ul. Kościerska 7, 80-328 Gdańsk, POLSKA } \\ & \text { Wojciech Sulisz } \\ & \text { sulisz@ibwpan.gda.pl } \\ & \text { Institute of Hydro-engineering, Polish Academy of Sciences } \\ & \text { ul. Kościerska 7, 80-328 Gdańsk, POLSKA } \\ & \text { Rohan Soman } \\ & \text { Institute of Fluid Flow Machinery, Polish Academy of Sciences } \\ & \text { 14, Fiszera Street Gdansk 80-231, Poland }\end{array}$

